\title{
La propuesta de ciudadanía democrática en Hannah Arendt
}

\author{
José Francisco JiMÉNEZ DÍAZ \\ Departamento de Derecho Público. Universidad Pablo de Olavide \\ josefco@upo.es
}

Recibido: 22-04-2013

Aceptado: 22-10-2013

Resumen: El objetivo fundamental del presente artículo es analizar la propuesta de ciudadanía ideada por Hannah Arendt. La tesis central es que dicha propuesta posibilita el desarrollo y fortalecimiento de la acción política en las democracias contemporáneas. El trabajo se divide en cinco epígrafes. En el primero, se desarrolla una breve introducción sobre el tema tratado. En el segundo y tercer epígrafe, se exponen, respectivamente, las condiciones políticas y morales que hacen posible la ciudadanía democrática, así como las condiciones que obstaculizan el ejercicio de la misma, de acuerdo con Arendt. Después, se reflexiona críticamente sobre la propuesta de ciudadanía arendtiana. Por último, se concluye y se propone un conjunto de desafíos cívicos en las democracias actuales a la luz de la referida propuesta..

Palabras claves: Arendt, Ciudadanía, Acción, Pluralidad, Democracias contemporáneas

\section{The proposal of democratic citizenship in Hannah Arendt}

\begin{abstract}
The main purpose of this paper is to analyze Hannah Arendt's citizenship proposal. The central thesis is that this proposal is possible in contemporary democracies, and it is adequate for developing and strengthening of political action. The work is divided in five sections. In the first, we develop a brief introduction on the studied issue. In the second and third section, we analyze, respectively, political and moral conditions that enable democratic citizenship, and the conditions that hinder the exercise of the same, according to Arendt. Then, we reflect critically on Arendt's citizenship proposal. Finally, we conclude and we propose a set of civic challenges relate to current democracies in light of the above proposal.
\end{abstract}

Key words: Arendt, Citizenship, Action, Plurality, Contemporary democracies.

\section{Referencia normalizada}

Jiménez Díaz, F. (2013). “La propuesta de ciudadanía democrática en Hannah Arendt”. Política y Sociedad, Vol.50 Núm. 3 937-958

Sumario: 1.Introducción. 2.Condiciones políticas y morales de la ciudadanía democrática. 3.Condiciones que dificultan la ciudadanía democrática. 4.Reflexión crítica sobre la propuesta ciudadana de Arendt. 5. A modo de conclusión: desafíos cívicos en las democracias contemporáneas. Bibliografía 


\section{Introducción $^{1}$}

Para Hannah Arendt (1906-1975), la noción de ciudadanía es previa a la forma política del Estado-nación, pues la primera se fundamenta en la tradición de pensamiento y experiencias políticas forjadas en la Grecia democrática de la antigüedad. Por ello, su obra se inspira en un conjunto de preguntas referidas a la ciudadanía que ya se planteaban pensadores como Aristóteles, a saber: ¿cuáles son las condiciones de la acción política?, ¿cuáles son los principios de la acción política?, ¿qué es la libertad?, ¿tiene la política todavía algún sentido? (Arendt, 2008: 131-150; Young-Bruehl, 2006: 408). En efecto, todas estas preguntas recorren las principales obras políticas de la citada autora, como son: Los orígenes del totalitarismo (1951 / $2001)^{2}$, La condición humana (1958 / 2005), Sobre la revolución (1963 / 2006) y ¿Qué es la política? (1959 / 2008) ${ }^{3}$, siendo estas obras las principales fuentes para el estudio aquí desarrollado.

El propósito principal de este artículo es analizar la propuesta de ciudadanía democrática desarrollada por Hannah Arendt en dichas obras, entendiendo que tal propuesta trata de establecer unos límites o condiciones de posibilidad para el ejercicio de la libertad política, considerando tanto los derechos (leyes) y las instituciones, como las responsabilidades y acciones (acción política) que han de desarrollar los seres humanos en el espacio público. Asimismo, se estudian las condiciones políticas que empecen y/o dificultan la práctica de la ciudadanía, a juicio de la pensadora alemana. En definitiva, la hipótesis planteada es que la ciudadanía en la reflexión arendtiana es concebida como un proceso moral y político y, por ende, dependiente de las cambiantes condiciones históricas y de las diversas acciones humanas. Tales condiciones históricas definen, en parte, el proceso de constitución moral y política de la ciudadanía no sólo en lo que respecta a su condición jurídicalegal, sino en cuanto a su práctica cotidiana y a las responsabilidades morales que lleva consigo. Desde estas coordenadas, Arendt propone una noción equilibrada y

${ }^{1}$ Este artículo se enmarca en las actividades del Proyecto de Investigación I+D+i "Derecho y Poder político: un análisis histórico y comparado desde la perspectiva de la persona” (DER2011-22560), financiado por el Ministerio de Ciencia e Innovación del Gobierno de España.

${ }^{2}$ Entre paréntesis se detalla: primero, el año de publicación original de la obra de Arendt y, luego, el año de publicación de esa misma obra en la versión aquí trabajada y citada. Se procede de la misma forma para citar las obras de Kant, Montesquieu y Tocqueville estudiadas por la pensadora alemana.

${ }^{3}$ En este trabajo, se cita la versión del ensayo “¿Qué es la política?” publicada en el siguiente libro de Hannah Arendt: La promesa de la política, Barcelona, Paidós, 2008, páginas 131-228. Dicho libro incluye, además de una introducción de Jerome Kohn (páginas 1137), varios estudios sobre: "Sócrates"; "La tradición de pensamiento político"; "La revisión de la tradición por Montesquieu”; “De Hegel a Marx” y "El final de la tradición” (páginas 43-129). 
democrática de ciudadanía en la que destaca la participación ciudadana y el cultivo de la virtud cívica.

En efecto, a juicio de Arendt, la ciudadanía democrática depende de un conjunto de condiciones políticas y morales que pueden ser destruidas o cuestionadas muy fácilmente. Es decir, las condiciones que contribuyen al desarrollo de la ciudadanía no aparecen en cualquier contexto político y lugar, pues no toda experiencia de lo político favorece la ciudadanía. Como dijera Aristóteles "el ciudadano no lo es por habitar en un lugar [...]; ni tampoco lo son necesariamente los que disfrutan de derechos jurídicos como para entablar juicio o ser juzgados [...] El ciudadano [...] se define mejor por su participación en la justicia y en el gobierno" (Aristóteles, 2007: 1275a). El ciudadano, remacha Aristóteles, es a quien le está permitido compartir el poder deliberativo y judicial, pues el primero ha de participar en el gobierno de la politeya, es decir, gobernar y ser gobernado; se es ciudadano/a en la medida que se puede y se elige obedecer y mandar para construir una vida conforme a la virtud. Desde esta tradición de pensamiento, por un lado, se ha argumentado que "las instituciones de la libertad constitucional no son más valiosas que lo que la ciudadanía haga con ellas" (Habermas, 1992: 7) y, por otro, se ha insistido en que "la práctica de las virtudes y de la ciudadanía plena no pueden desligarse del desarrollo del yo" (Clarke, 2010: 132). Por su parte, Kymlicka y Norman (1994) han defendido una concepción realista de la ciudadanía, la cual requiere un equilibrio entre derechos y obligaciones de los ciudadanos, así como considerar las condiciones de posibilidad en las que pueda desarrollarse.

\section{Condiciones políticas y morales de la ciudadanía democrática}

En la obra de Arendt hay tres autores modernos que orientan su pensamiento político y, por ende, su propuesta de ciudadanía democrática. Estos autores son Kant, Montesquieu y Tocqueville. Las ideas del filósofo alemán en su Crítica del Juicio (Kant, 1790 / 2007) inspiraron y ayudaron a Arendt a comprender el fenómeno de la pluralidad humana, así como el juicio político, tal y como se muestra más adelante. Los citados pensadores franceses estudiaron detalladamente las instituciones políticas anglosajonas de su época. Por un lado, Montesquieu, en su obra Del espíritu de las leyes (Montesquieu, 1748 / 1987), se dedicó al estudio de la naturaleza y los principios de acción que caracterizan las distintas formas de gobierno, con especial atención al sistema político inglés de su tiempo. Dicha obra de Montesquieu propició que Arendt comprendiera la relevancia de las instituciones políticas para el ejercicio de la libertad y del poder desde la perspectiva ciudadana. Por otro lado, Tocqueville fue un gran admirador y analista de la República estadounidense desde su fundación hasta bien entrado el siglo XIX, como así relata en La democracia en América (Tocqueville, 1835-1840 / 2006). La obra de Tocqueville contribuyó a que Arendt analizara e identificara los límites de la libertad política en las sociedades modernas, como se muestra en el tercer epígrafe. Además, el objetivo común de las citadas obras de Montesquieu y Tocqueville era estudiar las bases culturales y 
sociales que posibilitan la libertad política, así como analizar el sistema de equilibrios, poderes y contrapoderes de los regímenes constitucionales.

Por consiguiente, Hannah Arendt no elaboró una teoría sistemática de la ciudadanía, al modo de la Ciencia Política contemporánea, pero sí se preocupó, a lo largo de su obra, por estudiar las experiencias políticas que posibilitaron el surgimiento de la ciudadanía en la modernidad, así como por el examen de los procesos sociopolíticos que llevaron a la negación y destrucción de la ciudadanía y de la libertad política. En su reflexión, se observa un interés especial por el estudio de los acontecimientos históricos que forjaron al ciudadano moderno occidental, lo que le lleva a analizar las condiciones y desafíos que favorecen -o empecen- el desarrollo de la ciudadanía. De este modo, en la teoría política arendtiana aparece "la pregunta por el ciudadano", como "cuestión política por excelencia [...], porque los ciudadanos crean la polis a cada instante, la moldean, la derrumban o la componen" (Alonso, 2012: 183).

Por ello, Hannah Arendt ve en los asuntos políticos un quehacer fundamental de los propios ciudadanos que, en cualquier caso, éstos no deben abandonar a su suerte, puesto que desentenderse de ellos implica perder la libertad. La libertad, para ella, es el sentido fundamental de la política y también es autonomía en su sentido literal; comporta la tarea de crear la norma a partir de uno mismo. Y este crear la norma a partir de uno mismo sólo aparece en el ámbito de la acción ciudadana, la cual se materializa en una esfera pública y en interacción con las demás personas (Flores D’Arcais, 2006). Así, el conjunto de su obra constituye una llamada a desplegar una idea positiva de la política que puede interpretarse como sinónimo de la democracia en su sentido etimológico (Bokiniec, 2009). Para Arendt, la política debe ser ejercida por una ciudadanía responsable y plural que esté dispuesta a llegar a acuerdos sobre los asuntos que le son comunes, sin ser tutelada por ningún agente exterior a ella misma. El hilo conductor de toda su obra es la recuperación del sentido de la acción política como la más excelente actividad humana, lo cual implica la rehabilitación del juicio político de la ciudadanía y del espacio público en que tal juicio puede expresarse. A su modo de ver, la acción política "descansa en la presunción de que podemos producir la igualdad a través de la organización, porque el hombre puede actuar en un mundo común, cambiarlo y construirlo, junto con sus iguales y sólo con sus iguales” (Arendt, 2001: 380), con todos los desafíos que ello supone.

De esta manera, la política constituye una promesa en la que el protagonismo de la ciudadanía y su participación efectiva son factores decisivos para el desarrollo de la esfera pública (Arendt, 2008). De hecho, a juicio de Arendt, la misma promesa de la política implica las acciones ciudadanas (Alonso, 2012: 199; Bokiniec, 2009: 7778), por lo que las condiciones de posibilidad de ambas están en consonancia. El análisis detallado de tales condiciones, según los argumentos aquí desarrollados, permite valorar si en las sociedades democráticas contemporáneas aparecen, o no, las circunstancias apropiadas para que los ciudadanos puedan convivir en un apropiado equilibrio entre libertad e igualdad.

Cuando Arendt piensa en las condiciones que hacen posible el ejercicio de la ciudadanía democrática, no se deja arrastrar por la nostalgia del ideal de la pequeña 
polis griega de la antigüedad. Más bien, la pensadora revela la adecuación de su análisis para entender el complejo escenario de las democracias liberales contemporáneas, como así han mostrado múltiples especialistas de su obra (Alonso, 2010 y 2012; Amiel, 2001; Baños, 2008; Bokiniec, 2009; Birulés, 2007; Caloz-Tschopp, 2008; Cano, 2004; Canovan, 1992; Cruz, 2006; Eslin, 1996; Forti, 2006; Giner, 2006; Mattucci, 2012; Reyes-Mate, 2010; Roiz, 2003; Sánchez, 2003; Tassin, 1998; Villa, 2002; Young-Bruehl, 2006).

Así, en las siguientes páginas, se analiza sistemáticamente, por un lado, aquellas condiciones políticas y morales que, según Arendt, favorecen el desarrollo de la ciudadanía democrática en el contexto de las sociedades contemporáneas; y, por otro, se examinan los posibles obstáculos para la aparición y práctica de la ciudadanía en tales sociedades. Después, se elabora una reflexión crítica sobre la propuesta arendtiana de ciudadanía. Y por último, de la mano de dicha reflexión, se presenta la conclusión y se delibera sobre algunos desafíos políticos que han de abordar los/as ciudadanos/as de las presentes democracias.

\subsection{Constitución, leyes y separación de poderes: el acto de fundación}

Sin duda, Arendt desarrolla una concepción genuina del poder político, tal y como expone en las siguientes frases sobre el Barón de la Brède: "El descubrimiento de Montesquieu concernía, en realidad, a la naturaleza del poder [...] El descubrimiento, contenido en una frase, apunta hacia el principio olvidado que sustenta toda la estructura de la separación de poderes: sólo 'el poder contrarresta al poder', frase que debemos completar del siguiente modo: sin destruirlo, sin sustituir el poder por la impotencia” (Arendt, 2006a: 203).

Además, para Arendt, la principal fuente del poder político es la ciudadanía unida (potestas in populo), la cual ha de estar sujeta a una ley fundamental o Constitución que le sirva de orientación en sus relaciones políticas. Por tanto, la Constitución y el derecho positivo derivado de la misma son los elementos normativos que han de facilitar el referido sistema de poderes y contrapoderes que configure un equilibro entre los diversos poderes sociales y políticos de un Estado. Así, del pueblo unido emana el poder político, pero la autoridad (auctoritas in senatus) procede de las leyes de que se dota la comunidad y de aquellos que las elaboran y aplican (legisladores y jueces). A juicio de Arendt, existen dos condiciones necesarias en el desarrollo de la ciudadanía democrática: por un lado, que la ciudadanía mantenga el poder para actuar (que no sea impotente); por otro, que los legisladores han de saber mantener y/o reconstruir la autoridad, sobre todo después de un proceso revolucionario. De tal modo, la fuente del derecho, según Arendt, debe ser "un documento escrito, estable y duradero, una Constitución” (Baños, 2008: 240). Y la Constitución no es sólo fuente del derecho, sino que en el mundo moderno también se identifica con "el acto de fundación” de un espacio público; es decir, con la potencialidad que tienen los seres humanos de iniciar algo nuevo con sus acciones (Arendt, 2006a: 165). Ese acto de fundación tendrá que ser paulatinamente recorda- 
do y actualizado para que los ciudadanos, que conviven en diferentes contextos, puedan darle el sentido moral y político apropiado.

Por tanto, la Constitución, aún siendo estable y duradera, se podrá ver e interpretar desde diversas perspectivas, ya que la comunidad política es plural y cambiante temporalmente. Incluso, la Constitución podrá cambiarse y ser enmendada de acuerdo a las variadas contingencias sociopolíticas, pues: "las enmiendas a la Constitución aumentan e incrementan las fundaciones originales de la República americana; no es necesario decir que la autoridad de la Constitución americana reside en su capacidad originaria para ser enmendada y aumentada” (Arendt, 2006a: 278).

Pero la Constitución es también el mecanismo normativo que asegurará cierta estabilidad en las relaciones políticas (Baños, 2008: 240). Por lo tanto, la pensadora alemana, además de reivindicar la validez y potencialidad del proyecto político y constitucional de la República norteamericana, que cumplió doscientos años de historia a finales del siglo XX, está reclamando el anclaje de la acción política en un entramado político-normativo que haga previsible el poder y, así, evitar el surgimiento de posibles tiranías. La fragilidad de la acción humana, su carácter impredecible y contingente, supone que cada nuevo acto de fundación surja sin garantizar el éxito; "que la más libre de las acciones políticas puede acabar trayendo el bien pero también el mal” (Villa, 1998: 15). Por ello se confía en el gobierno de las leyes y no tanto en el de las personas.

\subsection{Discursos y acciones: las acciones libres y deliberadas}

La influencia de Aristóteles en Arendt es más que notable, pues ella reclama "la idea aristotélica de que solamente dos actividades pueden considerarse políticas: el discurso (lexis) y la acción (praxis)" (Cano, 2004: 35). En efecto, a juicio de Arendt, la política es una acción construida conjuntamente entre ciudadanos libres e iguales que utilizan sus ideas, palabras y discursos. Mantener este amplio concepto de política implica no confundirla con el mero ejercicio del gobierno, el poder y la violencia. El miedo, la fuerza y la violencia han sido incluidos en muchas definiciones como elementos fundamentales del concepto de política, debido a que como "nuestras experiencias con la política se han dado sobre todo en el campo de la violencia, nos parece natural entender la acción política según las categorías del coaccionar y ser coaccionado, del dominar y ser dominado [...]" (Arendt, 2008: 223). De hecho, tales experiencias políticas han llevado a que la idea de libertad política haya perdido sentido. De modo que durante el siglo pasado "las guerras y las revoluciones, no el funcionamiento de los regímenes parlamentarios y los partidos democráticos, constituyen las experiencias políticas fundamentales” (Arendt, 2008: 216).

Sin embargo, la política, en tanto acción humana "trata del estar juntos y los unos con los otros de los diversos" (Arendt, 2008: 131). Es decir, al hacer política se trata de establecer relaciones entre personas pertenecientes a una comunidad diversa y plural, que tratan de mantener cierto sentido de comunidad. Ello hace que Arendt se interese por el estudio de los diversos modos de pluralidad humana y las 
instituciones que les corresponden; estudio iniciado por Aristóteles en la antigüedad y continuado, entre otros pensadores, por Kant en la Ilustración. Precisamente, Kant no dió por sentadas las distinciones entre gobernantes y gobernados, entre elite y masa, y pensó que la condición de la pluralidad humana implicaba que los hombres no podían reducirse a la unicidad (el hombre), sino que más bien eran "muchos, y todos diferentes entre sí" (Young-Bruehl, 2006: 409).

Así, para ella, la política no tiene como elemento definitorio a la violencia física y/o simbólica, al gobierno o al poder mismo. Más bien, la política surge de las relaciones entre las personas que haciendo uso prudente de sus palabras e ideas tratan de resolver los conflictos por medios pacíficos. Si prevalecieran los medios violentos e ideológicos para resolver los conflictos humanos no tendría sentido hablar de política; más bien habría que hablar de guerra y/o de adoctrinamiento ideológico. Por ello, en la Grecia clásica: "Ser político, vivir en una polis, significaba que todo se decía por medio de palabras y de persuasión, y no con la fuerza y la violencia [...] obligar a las personas por medio de la violencia, mandar en vez de persuadir, eran formas prepolíticas” (Arendt, 2005: 53).

En esa dirección, la política, para Aristóteles, Kant y Arendt, resulta de aceptar la existencia de grupos diferentes, intereses múltiples, tradiciones y opiniones diversas en la ciudad. Por ello, la política sólo es una de las posibles respuestas a los conflictos humanos y no es, ni mucho menos, la más habitual. Otras respuestas pueden ser la oligarquía y la tiranía. Pero estas últimas destruyen la pluralidad de la polis en beneficio de la minoría en el poder (Crick, 2000: 3-4). Así, en el momento que "se pierde la contigüidad humana, es decir, cuando las personas sólo están a favor o en contra de las demás, por ejemplo durante la guerra [...] el discurso se convierte en `mera charla' $[. .$.$] ya sirva para engañar al enemigo o para deslumbrar$ a todo el mundo con la propaganda; las palabras no revelan nada” (Arendt, 2005: 209).

Por tanto, Hannah Arendt diferencia entre violencia, gobierno y política, pues las reglas que rigen cada uno de estos fenómenos son diferentes. Reconocer la pluralidad y la diversidad que caracteriza a los seres humanos mediante sus discursos no es obstáculo, sino que favorece cierta igualdad a la hora de decir y decidir sobre el mundo común. En ese sentido, Aristóteles expuso en su Política: "Sólo el hombre, entre los animales, posee la palabra [...] la palabra [logos] existe para manifestar lo conveniente y lo dañino, así como lo justo y lo injusto. Y esto es lo propio de los humanos frente a los demás animales: poseer, de modo exclusivo, el sentido de lo bueno y lo malo, lo justo y lo injusto, y las demás apreciaciones” (Aristóteles, 2007: 1253a).

\subsection{Juicio político y responsabilidad ciudadana en la esfera pública}

Para Aristóteles, tener palabra (logos) comporta distinguir entre lo justo y lo injusto, lo bueno y lo malo; pero no entre lo verdadero y lo falso. Lo cual implica que el conocimiento referido a los asuntos humanos no es un saber objetivo y exacto, sino 
"un conocimiento que orienta al ser humano en sus preferencias y en la elección de sus acciones" (Ramírez, 2008: 16). Es un conocimiento sobre lo que puede ser de otra manera, que tiene que ver con saber elegir entre opciones, en principio, igualmente valiosas y que, por tanto, solo mediante la deliberación pública y la confrontación de diversos juicios políticos se podrá adoptar la decisión que sea más conveniente, aunque nunca pueda satisfacer a todos. Así, la tarea de elaborar un juicio político en la esfera pública, la cual "radica en la simultánea presencia de innumerables perspectivas y aspectos en los que se presenta el mundo común y para el que no cabe inventar medida o denominador común” (Arendt, 2005: 77), es decisiva para ejercer la ciudadanía.

La facultad de juzgar, en Arendt, exige una reflexión profunda sobre la contingencia y mudanza de los asuntos humanos, la idea de libertad y su vinculación a la "esencial pluralidad de lo público-político" (Sahuí, 2002: 248). Esta reflexión se hace ineludible porque el juicio político es una tarea compartida que requiere conocer las perspectivas de las otras personas que aparecen en público; las opiniones de los demás ciudadanos. Y, por ello, el diálogo entre éstos es primordial en el proceso de juzgar. De esta forma, para Arendt, la capacidad de juicio requiere de la "perspectiva del otro" y un "pensamiento ampliado" que brinda un sentido de comunidad. El juicio es ante todo una tarea colectiva en la que se ha de contar con los otros, pero también "una facultad mental clave para la política de acuerdo con Arendt" (Marshall, 2010: 368). El juicio se aproxima más a la "vita activa” y a la esfera pública creada entre los hombres, que a la vida contemplativa (Arendt, 2002: 456). Así, el juicio es la forma particular que el pensamiento adopta en el mundo político y como la capacidad de juzgar es la más política de las capacidades mentales se requiere, para su desarrollo, tanto el diálogo consigo mismo de cada ciudadano (pensar), como los diálogos entre éstos para conseguir ver desde las perspectivas de las demás personas. Por tanto, la facultad del juicio consiste en "juzgar particulares, sin subsumirlos bajo reglas generales que se enseñan y se aprenden hasta que se convierten en hábitos que pueden ser sustituidos por otros hábitos y reglas” (Arendt, 2007: 184).

Algunas de estas ideas las descubrió Kant en su Crítica del Juicio (1790 / 2007), donde el filósofo ilustrado desarrolló una visión innovadora de la sociabilidad y libertad humanas. Así, Kant expone que el juicio estético consiste en pensar poniéndose en el lugar de los demás y conseguir de este modo un pensamiento más ampliado (Arendt, 2002: 455-456). Esta ampliación del pensamiento, según Kant: "Se realiza comparando [nuestro] juicio con otros juicios no tanto reales, como más bien meramente posibles, y poniéndose en el lugar de cualquier otro" (Kant citado en Arendt, 2002: 455). Es lo que Kant concibió como ejercer el juicio reflexivo que, en sociedades muy cambiantes, se torna en una tarea continua en la cual se fusionan las capacidades de juzgar y de actuar en un "acto-momento ético-político” (Clarke, 2010: 117).

De acuerdo con Arendt, el poder del juicio reflexivo reside en el convenio potencial con los demás, “de manera que no se mantiene el diálogo de cada uno consigo mismo que comporta la actividad reflexiva, sino que este diálogo se hace exten- 
sivo a otros. Así, es el diálogo anticipado con los demás lo que domina la estructura del juicio y es de ahí de donde el juicio extrae su fuerza y su potencial validez" (Del Águila, 2009: 22). Por ello, el juicio requiere pensar con imaginación en lo que seres humanos hacen, puesto que la imaginación ayuda a representar lo que puede ser de otra manera; a construir una visión alternativa mediante ejemplos y consideraciones morales (Mattucci, 2012: 178-221). Argumenta la autora que: "Sin imaginación, el juicio es ciego; sin juicio, la imaginación está vacía” (Arendt, 2006b: 661). Además, Arendt relaciona la facultad del juicio político con la dignidad humana, pues si el primero es libre y voluntario favorece la aparición de la segunda.

En suma, en Arendt, se aprecia cierta reconciliación, no exenta de tensiones, entre el juicio reflexivo kantiano y la visión aristotélica de la phrónesis, vinculada esta última al contextualismo y narrativismo (Sahuí, 2002: 259). La phrónesis es la virtud central de la política para los pensadores clásicos griegos y se asienta en la elección de la alternativa más conveniente en cada situación particular. Es decir, consiste en la capacidad que poseen los seres humanos para discernir lo más apropiado en una situación concreta y para ello se requiere experiencia y educación cívica.

\subsection{Principios y virtudes cívicas en la comunidad política}

Para Arendt, la ciudadanía democrática consiste, antes que nada, en una forma de vida en donde los ciudadanos han de poder "alzar la voz y asociarse con criterio propio e independencia política” (Baños, 2008: 22), permitiendo ello la construcción de un espacio público libre e igualitario que ha de ser protegido y garantizado por la propia acción cotidiana de los ciudadanos. Éstos han de ser educados y socializados en costumbres, hábitos, virtudes y principios de acción acordes a la cultura política en la que habrán de convivir. Ésta será una cultura política que privilegie el diálogo y la discusión para llegar a acuerdos entre los ciudadanos y así poder dirimir sus conflictos e intereses pacíficamente en la esfera pública. Por ello, en esta esfera no tienen cabida las actitudes violentas o las imposiciones por la fuerza. Las principales herramientas de los ciudadanos son el discurso y la acción, que han de ser ejercidas en un espacio compartido de libertad e igualdad, ya que "el mérito del ciudadano en una república consiste en no ser más notorio en los asuntos públicos que sus conciudadanos, lo cual constituye su virtud" (Arendt, 2008: 101. Subrayado de la autora). No obstante, desarrollar tal virtud cívica y cultivar la libertad política requieren responsabilidad y esfuerzo de la ciudadanía.

Así, es necesario educar a los nuevos ciudadanos en las virtudes y principios pertinentes para desarrollar la referida cultura política, pues las conquistas democráticas conseguidas en el pasado, además de ser frágiles, no han de caer en el olvido. Por tanto, la ciudadanía ha de ser educada en una forma de vida y valores republicanos que antepongan y prioricen el bien común-público por encima del bien particular. Los ciudadanos han de saber anteponer los intereses comunes a sus intereses particulares: lo contrario comporta corrupción y degradar el espacio público. Por 
eso el sentido etimológico de república (res publicae: los asuntos públicos) adquiere un relevante significado en el pensamiento republicano que redefine Hannah Arendt (Canovan, 1992; Giner, 2006).

Asimismo, el principio orientador de las relaciones políticas en una república democrática, para Arendt, es el principio del amor a la igualdad en libertad, el cual posibilita "la existencia de relaciones políticas basadas en el respeto, el reconocimiento mutuo y la deliberación de las diferencias” (Baños, 2008: 269-270). Todo lo cual permite la construcción de un espacio público que fundándose en las leyes, los hábitos y costumbres de los ciudadanos garantiza la libertad y la pluralidad, pues la pensadora alemana "concibe la política como un espacio para armonizar las diferencias que nunca van a dejar de existir" (Cano, 2004: 31), puesto que "la distinción y la igualdad son los dos elementos constitutivos de los cuerpos políticos" (Arendt, 2008: 98). Por ello, Arendt reinterpreta la tradición de pensamiento republicano y le otorga consistencia y sentido en el complejo contexto de las democracias liberales del siglo XX. Tarea que en sí misma merece especial atención, sobre todo a tenor de las diversas y grandes crisis que se han interpuesto en el devenir de las democracias liberales y en la práctica de la ciudadanía democrática durante el siglo pasado y los tiempos presentes (Rodríguez-Guerra, 2013).

\section{Condiciones que dificultan la ciudadanía democrática}

Arendt es plenamente consciente de las dificultades y/o barreras que han existido a lo largo de la historia de las democracias para cumplir con sus ideales y, lo que es más importante, de los peligros que han llevado a su negación y destrucción. Por ello, no se puede olvidar que entre sus primeras preocupaciones se hallan el estudio de los diversos fenómenos ligados a los totalitarismos del siglo XX y la génesis histórico-política de los mismos. Así, a juicio de una estudiosa de Arendt, la motivación primordial de su pensamiento político consistió en evitar que cualquier tipo de experiencia totalitaria volviera a repetirse en la historia (Canovan, 1992). Arendt interiorizó de tal forma dicha motivación que gran parte de su vida intelectual la consagró al conocimiento de las causas que llevaron al totalitarismo (Flores D’Arcais, 2006; Sánchez-Capdequí, 2012).

\subsection{El peligro del “absoluto” en la esfera pública}

En toda esfera pública existe el peligro de los ideales absolutos que, en muchas ocasiones adornados de buenas intenciones, pueden destruir en muy poco tiempo lo que llevó décadas o siglos construir y sostener (Constitución, instituciones, virtudes cívicas), pues como expuso la pensadora: "La tragedia consiste en que las leyes son hechas para los hombres, no para los ángeles ni para los demonios. Las leyes y todas las 'instituciones duraderas' se arruinan no sólo por la embestida de la maldad 
elemental, sino también por el impacto de la inocencia absoluta [...] Introducir el absoluto en la esfera de la política [...] significa la perdición” (Arendt, 2006a: 112).

El proceso de cambio político que se inicia con la Revolución Francesa es un claro ejemplo, para Arendt, del modo en que los ideales absolutos se incorporan a la esfera pública y llevan a la destrucción de toda posibilidad de estabilización de una vida realmente respetuosa con la pluralidad y libertad política. Así, en dicha revolución sucede la siguiente metamorfosis: el poder absoluto del monarca francés (Rey Luis XVI) es sustituido por el concepto de "voluntad popular", de tal modo que este nuevo concepto empieza a ser fácilmente manipulable por los revolucionarios cuando éstos se convierten en líderes despóticos e intentan imponer una única voz ávida de interpretar los ideales revolucionarios, al tiempo que se atribuye una total unanimidad al "pueblo" (le peuple). En este proceso de sustitución de ideales absolutos jugaron un papel fundamental los hombres de letras o los "filósofos" que introducían ideas abstractas en la arena política sin hacerse cargo de sus consecuencias prácticas. Este hecho ya fue advertido por Tocqueville, en sus análisis del proceso revolucionario francés, y Arendt trató de reinterpretarlo para comprender el desarrollo contemporáneo de las revoluciones. He aquí la argumentación de Arendt al respecto: "también la idea de Rousseau de una 'Voluntad General' que inspiraba y dirigía la nación, como si esta formase realmente una persona y no estuviera compuesta de una multitud, llegó a constituir un axioma para todos los partidos y facciones de la Revolución francesa, porque era un sustitutivo teórico de la voluntad soberana del monarca absoluto" (Arendt, 2006a: 212).

Por tanto, del anterior razonamiento se deriva una importante idea que la propia Arendt destaca en Sobre la revolución, y que consiste en que el error teórico fatal que cometieron los hombres al servicio de la Revolución francesa "fue creer, de modo casi automático y acrítico, que el poder y el Derecho tenían su origen en la misma fuente [es decir, en el pueblo]" (Arendt, 2006a: 224). Otro error, relacionado con el anterior, fue considerar, como hizo Karl Marx, que "la pobreza también puede constituir una fuerza política de primer orden” (Arendt, 2006a: 82), pues se percibían en los pobres -básicamente los proletarios con conciencia de clase- a los auténticos hombres llamados a liberar a la humanidad de las cadenas de la necesidad. Ello supuso en el plano teórico la "transformación de la cuestión social en fuerza política” (Arendt, 2006a: 82), y en el plano práctico la exclusión de cualquier otro actor político en el espacio público y la negación de la pluralidad y la libertad. Así, "el objetivo de la revolución cesó de ser la liberación de los hombres de sus semejantes, y mucho menos la fundación de la libertad, para convertirse en la liberación del proceso vital de la sociedad de las cadenas de la escasez [...] El objetivo de la revolución era ahora la abundancia, no la libertad” (Arendt, 2006a: 84).

Por ello, el auge de la cuestión social y los principios revolucionarios en la esfera política impulsan la "desmundanización” o pérdida del mundo común (Arendt, 2008: 225) e impiden a los seres humanos pensar por sí mismos. Además, Arendt es consciente, como ya lo fue Tocqueville, de que "de todas las ideas y sentimientos que prepararon la Revolución, la idea y el gusto por la libertad pública en sentido 
estricto han sido los primeros en desaparecer” (Tocqueville citado en Arendt, 2006a: 176).

\subsection{La cuestión social, el avance del individualismo y la aparición del burgués}

El análisis de la cuestión social moderna es uno de los asuntos más controvertidos en la obra de Hannah, pues muchos de sus intérpretes han visto contradicciones y lagunas en ella cuando trata el tema (Clarke, 2010; Pitkin, 1981; Wolin, 1983). No obstante, para comprender el alcance del pensamiento arendtiano, se ha de reconocer que de este pensamiento se deriva una teoría sociológica de la modernidad, la cual tiene ciertos paralelismos con el pensamiento weberiano, en cuanto ambos pensamientos ven en la política democrática el principal elemento que puede contrarrestar la pérdida del sentido y el declive de la libertad política en las sociedades modernas (Thaa, 2008: 9-40). De hecho, la progresiva incidencia de la cuestión social en la modernidad comporta un fuerte y claro deterioro de la esfera de la política, de acuerdo con Arendt. Así, el nacimiento de lo social produce la proliferación de intereses y necesidades privadas en la vida pública, pues los problemas asociados a la vida económica y a la satisfacción de las necesidades humanas "pasan a ser el contenido y motivo de la vida pública” (Baños, 2008: 37). Pero lo importante para Arendt, no es tanto estudiar el desarrollo e incidencia real de la cuestión social en la modernidad, sino más bien reflexionar sobre las consecuencias que tiene la primacía de lo social en la esfera política de las democracias contemporáneas. La principal consecuencia es que la libertad se separa de la esfera política en la modernidad, y el espacio público ya no está orientado por la política, sino por las exigencias que impone la cuestión social. Así, en la sociedad moderna se produce la "sustitución de la acción por la conducta y ésta por la burocracia, el gobierno personal por el de nadie [...] [y con] el auge de la sociedad [...] una de las notables características de la nueva esfera ha sido una irresistible tendencia a crecer, a devorar las más antiguas esferas de lo político y privado [...]” (Arendt, 2005: 67).

Otra consecuencia significativa del predominio de lo social en la modernidad es, al modo de ver de Arendt, que los hombres se convierten en seres fragmentados y atomizados, es decir, individuos aislados unos de otros, en los que se impone una libertad solipsista e individualismo exacerbado. Y con ello los seres humanos resultan desprovistos de las capacidades de ver y oír a los demás, así como de ser vistos y oídos por ellos. El individuo se encierra en su propia experiencia singular y se vuelve incapaz de crear algo en común con las demás personas. Así, la posibilidad de crear una ciudadanía democrática y responsable de su propio destino se torna en una quimera. Es el tiempo de la emergencia del individualismo moderno y de una sociedad burguesa muy competitiva, en la cual "lo privado se ha convertido en el único interés común que nos queda” (Cano, 2004: 57). Al referido individualismo, Hannah, lo denominará filisteísmo. Dice la pensadora que: "El retiro del filisteo a la vida privada, su devoción sincera a las cuestiones de la familia y de su vida profesional, fueron el último y ya degenerado producto de la creencia de la burguesía en 
la primacía del interés particular. El filisteo es el burgués aislado de su propia clase [...]" (Arendt, 2001: 421).

De este modo, a juicio de Arendt, la sociedad adquisitiva y competitiva forjada por la burguesía moderna ha generado apatía y hostilidad hacia la vida pública, pues dicha sociedad se fundaba "en un estilo y en una filosofía de vida tan insistente y exclusivamente centrados en el éxito y el fracaso del individuo, en la implacable competencia, que los deberes y responsabilidades de un ciudadano sólo podían considerarse como un innecesario drenaje de su tiempo y sus energías forzosamente limitados” (Arendt, 2001: 394).

En efecto, en las sociedades democráticas liberales se puede observar y comprobar que muchas de las anteriores ideas tienen gran vigencia para comprender la precariedad en que se halla la acción ciudadana. Y más aún con la actual crisis financiera y económica -vivida de forma especialmente dramática en la denostada Europa del sur- en la que las cuestiones económicas parecen dominarlo todo, y donde la esfera política es casi totalmente absorbida por las primeras.

\subsection{Desequilibrio de poderes y auge de los despotismos modernos}

Muchos de los despotismos vividos durante los tiempos modernos y contemporáneos se han derivado precisamente del excesivo aislamiento, individualismo e impotencia ciudadana para crear y proteger el espacio público con el debido esmero. La propia Hannah Arendt entiende en interdependencia dichos fenómenos, de tal modo que un mayor aislamiento e individualismo entre los ciudadanos, como se observa durante la modernidad, lleva a una creciente pérdida de poder (impotencia) de éstos. Si hay algo que acabe con la política democrática es la impotencia ciudadana o la incapacidad para construir y/o defender algo que es común entre la ciudadanía.

Alexis de Tocqueville, a quien Hannah se refiere explícita o tácitamente en sus obras, decía que la más eficaz garantía para que aparezca y se desarrolle el despotismo es el aislamiento, el individualismo y el egoísmo. Tocqueville mostraba que: "El individualismo es un sentimiento reflexivo y apacible que induce a cada ciudadano a aislarse de la masa de sus semejantes y a mantenerse aparte con su familia y sus amigos; de suerte que después de formar una pequeña sociedad para su uso particular, abandona a sí misma a la grande [...] El egoísmo seca la fuente de las virtudes; el individualismo, al principio sólo ciega las de las virtudes públicas; pero a la larga ataca y destruye todas las otras, y acaba encerrándose en el egoísmo [...] El individualismo es propio de las democracias, y amenaza con desarrollarse a medida que las condiciones se igualen” (Tocqueville, 2006: 128-129).

Aparte del elemento profético de la cita anterior, tanto para Tocqueville como para Arendt, el individualismo es un auténtico mal moral y político, pues vacía al ciudadano de su carácter cívico y hace de él un esclavo moderno. El momento histórico-político en que emerge el individualismo con mayor fuerza es después de una revolución "democrática”, y es sobre las ruinas de una aristocracia cuando más 
se acentúa y consolida el asilamiento entre los hombres. Así, Arendt cuestiona las supuestas conquistas democráticas que pudieron derivarse de la Revolución Francesa, pues las revoluciones inducen a los hombres a huir unos de otros y perpetúan en el seno de la igualdad los odios que engendrara la desigualdad (Tocqueville, 2006: 132). En este sentido, Arendt afirma que: "No sólo en la Revolución francesa, sino también en todas las revoluciones inspiradas en ella, el interés común apareció disfrazado de enemigo común, y la teoría del terror, desde Robespierre hasta Lenin y Stalin, da por supuesto que el interés de la totalidad debe, de forma automática y permanente, ser hostil al interés particular del ciudadano" (Arendt, 2006a: 105. Subrayado mío).

No puede olvidarse que el despotismo, de acuerdo con la clasificación de las formas de gobierno que concibió Montesquieu, está basado en el principio de acción derivado del miedo, el cual genera desconfianza entre la ciudadanía e impide la libre interacción de ésta y, por ende, destruye la acción política. Es decir, el despotismo implica falta de acción y de discursos autónomos por parte de los seres humanos, que pasan a convertirse en esclavos del tirano y a ser desprovistos de un espacio de aparición y de un espacio público. Desgraciadamente contra la posibilidad de que surjan grandes déspotas y tiranos no son inmunes las sociedades tardomodernas del siglo XXI, pues desde hace años se observa cómo se consolidan los partidos de extrema derecha por toda Europa, incluso en los países que atesoran una larga tradición democrática y gozan de mayor grado de bienestar (véase, por ejemplo, el ascenso de la extrema derecha en Francia).

\section{Reflexión crítica sobre la propuesta ciudadana de Arendt}

En la obra de Arendt se aprecia una clara tensión entre la dimensión moral y política de los seres humanos, en cuanto la acción política intenta ir más allá de los problemas morales y el establecimiento de una comunidad política implica la necesaria convivencia con otros sujetos y la construcción de un mundo común y, por tanto, un compromiso moral a largo plazo que nos vincula de forma inesperada (Walzer, 2004). Así, cuando Arendt (y Kant) se plantea la cuestión de las condiciones de posibilidad e imposibilidad de la ciudadanía (y de la política), tal cuestión se torna un asunto tanto político como moral que enriquece y torna más complejo el pensamiento de la autora.

La lectura atenta de la obra de Arendt lleva a apreciar que su noción de ciudadanía no es un simple elogio de los elementos positivos que contribuyen a su desarrollo, sino que la pensadora alemana es plenamente consciente de las dificultades y/u obstáculos que han existido y existen en las democracias para cumplir con sus ideales. Además, Arendt conoce la facilidad con la que las condiciones de posibilidad de la ciudadanía pueden ser destruidas y cuestionadas, como ella pudo comprobar durante su propia experiencia biográfica. Gran parte de su obra la dedicó al estudio de las condiciones que llevan al declive de la política y de la ciudadanía. Sin ir más lejos, en la Europa de este inicio de siglo, se observan diversas experiencias 
que llevan al declive del mundo común-público que la ciudadanía ha de desarrollar y compartir. Así, ese mundo común que, para Arendt, han de construir y cultivar los ciudadanos parece estar secuestrado por unos pocos, una elite de políticos profesionales y tecnócratas cada vez más alejados de la ciudadanía. Además, dicho mundo común es presentado, demasiadas veces, desde la perspectiva interesada de los poderes económicos y mediáticos dominantes, los cuales producen una democracia sin ciudadanos (Camps, 2010) en la que la voz de éstos es manipulada y usurpada (Maravall, 2013). Esta situación está relacionada con la crisis global de legitimidad política que parece provenir de bastante tiempo atrás (Castells, 2009).

Tal crisis de legitimidad política, en parte, es producida por la muy escasa o nula autonomía de la esfera política, la cual parece ser una prolongación de los intereses que se juegan en el campo de las grandes entidades financieras y económicas del mundo. El auge de lo económico lleva consigo un claro deterioro de la esfera política; cuando todo se convierte en mercancía surge una especie de totalitarismo económico y el campo de lo económico impone sus intereses a todas las esferas de la vida. Este escenario es el que lleva a Hannah a argumentar que la política prácticamente desaparece con el auge de lo social, que, para ella, también es lo económico. Por esto, en Arendt hay una clara intención de separar rígidamente la esfera política de la cuestión social. Esta separación ha llevado a que varios estudiosos se pregunten en qué lugar queda la justicia en el espacio político arendtiano (Pitkin, 1981; Wolin, 1983; Clarke, 2010), pues si en la esfera política no cabe tratar muchos de los problemas que afectan de lleno a los ciudadanos (pobreza, desigualdades, injusticias sociales, etc.), dónde y quiénes podrían tratar tales problemas. Precisamente, la propuesta de Arendt genera bastantes dudas al dejar la liberación de la pobreza, no en manos de la política, sino al albur de la tecnología y del conocimiento experto (Alonso, 2010: 314).

Sin embargo, en un contexto tan cambiante y complejo como el del presente siglo, es este auge de lo económico y de lo social lo que origina nuevas posibilidades de politización, pues de hecho diversos ciudadanos y movimientos sociales se resisten y luchan contra la colonización del mundo público-común por las relaciones de dominación que imponen tanto la llamada clase política como las grandes corporaciones económicas. Ahora bien, dichas posibilidades de politización sólo pueden materializarse si el interés individual se proyecta más allá de su inmediatez y aparece eso que Tocqueville llamó el interés bien entendido. Este interés no provoca grandes devociones, pero sugiere cada día pequeños esfuerzos y aunque no es capaz de hacer virtuosa a una persona, sí permite "formar gran número de ciudadanos ordenados, sobrios, moderados, previsores, dueños de sí mismos; de modo que, si no conduce directamente a la virtud por la voluntad, sí le acerca imperceptiblemente a través de los hábitos que inculca” (Tocqueville, 2006: 108-109). Así, se ha argumentado que "los intereses individuales pueden formar parte de la práctica de las virtudes cívicas dentro del contexto de la ciudadanía plena: una ciudadanía que se adentra en lo universal sin perder de vista las realidades de la vida" (Clarke, 2010: 121). 
En ese sentido, se observan en las sociedades democráticas gran diversidad de asociaciones civiles y movimientos sociales (ecologista, pacifista, feminista, etc.) que si bien reclaman y luchan por una serie de intereses grupales concretos, dichos intereses apuntan hacia la construcción de un mundo global más decente y justo. Por ello, el auge de lo social y la defensa de una serie de asuntos colectivos no impiden la politización de esos asuntos entre la ciudadanía, ni el desarrollo de las condiciones de posibilidad de esta última, sino que la nueva política y "la ciudadanía plena y el yo ciudadano surgen no a pesar de, sino gracias, a lo social” (Clarke, 2010: 123).

Por tanto, en el estudio de las condiciones de posibilidad de la ciudadanía han de considerarse, a su vez, las constricciones que imponen las diversas desigualdades sociales que se extienden no sólo en el ámbito de los estados nacionales, sino en el escenario de la sociedad global. Si bien la pertenencia a una familia, a una cultura, a un Estado o la vinculación que implica una relación moral, contribuyen a "la dependencia espiritual” (Walzer, 2004: 31) y, por tanto, suponen un deterioro de la libertad y autonomía que Arendt reclama para la política; asimismo, las relaciones de dominación y de desigualdad que se producen en el ámbito nacional e internacional menoscaban las posibilidades de desarrollo político y económico de los grupos sociales o países dependientes y empobrecidos. En estos grupos sociales o países no pueden surgir las condiciones morales y políticas para el desarrollo de la ciudadanía, pues entre sus mayores obstáculos están precisamente la pobreza y el analfabetismo de la mayoría de las personas que conforman dichos grupos o viven en tales países, en los que, a su vez, se muestra una quiebra entre la supuesta condición ciudadana y la dignidad humana.

Por ello, también se han de politizar las referidas relaciones de dominación y desigualdades globales que hacen a unas sociedades dependientes de otras, puesto que las condiciones ideales de la ciudadanía sólo parecen materializarse en los Estados dominantes del escenario mundial. Estados que, cada vez más, vigilan sus fronteras y levantan muros a las personas que buscan una vida decente lejos de sus lugares de nacimiento. En otras palabras: para pensar las condiciones que hacen posible la ciudadanía también se han de establecer una serie de límites a las desigualdades reales producidas y reproducidas por los Estados-nación en la sociedad global. De lo contrario, la democracia y la ciudadanía pueden tornarse en pequeñas islas en un gran océano.

\section{A modo de conclusión: desafíos cívicos en las democracias contemporáneas}

De acuerdo con lo aquí argumentado, la propuesta de ciudadanía democrática arendtiana se configura sobre las siguientes experiencias políticas relacionadas y/o condiciones de posibilidad. La primera experiencia política consiste en el acto de fundación a partir del cual se organiza la comunidad política: tal acto origina la Constitución y las leyes. A su vez, este marco normativo e institucional debe estar arraigado en los discursos y acciones deliberadas de la ciudadanía, y en la capaci- 
dad de ésta para juzgar los asuntos públicos: he aquí dos experiencias claves de la ciudadanía. Además, la virtud cívica definida por el amor a la igualdad en libertad es otra experiencia política principal, pues sólo mediante tal virtud es posible desarrollar la acción política y la pluralidad humana. Sin embargo, la ciudadanía democrática, sustentada sobre la propia acción política, puede ser destruida por tres experiencias antipolíticas y antidemocráticas como son: la defensa de ideales absolutos, el creciente individualismo y el auge de los despotismos; todo ello margina la acción y la pluralidad.

Para Arendt, la acción política se arraiga en la confianza mutua de la ciudadanía (Arendt, 2006b), pero la moderna deriva de las democracias ha degradado progresivamente tal confianza. Así, la creciente desconfianza entre la ciudadanía, como consecuencia de las citadas experiencias antipolíticas, produce un proceso por el que el poder político se vacía de su potencial efectivo y los ciudadanos -muchas veces, meros súbditos- pasan a tener un papel de simples espectadores y/o sufridores. Este puede ser el nuevo caldo de cultivo para que reaparezcan los totalitarismos, como riesgos que se acumulan durante el eclipse de las democracias liberales (Flores D`Arcais, 2006). Efectivamente, un politólogo norteamericano ha mostrado el avance del "totalitarismo invertido", el cual se origina cuando los ciudadanos abandonan "su intensa participación en los asuntos comunes de sus comunidades para favorecer sus fines personales" (Wolin, 2008: 126) en sistemas aparentemente democráticos. No en vano, Tocqueville imaginó que el despotismo era posible allí donde los ciudadanos elegían no participar.

De tal modo, contrariamente a las promesas modernas de la ciudadanía y de los ideales democráticos, buena parte de las democracias contemporáneas están dirigidas por elites políticas y económicas sin considerar los intereses comunes de los ciudadanos, pues las primeras parecen gobernar de espalda a los segundos, ya que gran parte de éstos han renunciado a su poder participativo. Así, el hecho de que en Grecia e Italia se impusieran gobiernos dirigidos por tecnócratas estuvo precedido por mucho tiempo de dudas y divisiones, falta de coraje y de visión política para afrontar los problemas comunes de la Unión Europea. A tenor de ello se difundió una creciente desconfianza ciudadana, tanto hacia las democracias nacionales como hacia el propio proyecto europeo (Torreblanca, 2011), que en España desembocó en el Movimiento de los indignados el 15 de mayo de 2011; movimiento que tuvo una gran repercusión en Europa y otras partes del mundo. A estos hechos se suma un elemento preocupante desde el punto de vista del liderazgo político democrático. Pues mientras dicho liderazgo sigue anclado en lo local, ámbito donde los políticos prometen y los ciudadanos votan, la acción de los líderes debe responder a actores y dinámicas internacionales en cuyo seno se imponen los intereses de los estados más poderosos atendiendo a supuestos criterios técnicos y objetivos mientras los principios democráticos-políticos se diluyen (Vallespín, 2012).

Ante este complejo e incierto contexto se hace necesario repensar el conjunto de experiencias que favorecen la aparición y práctica de la ciudadanía democrática tanto en el ámbito del Estado nacional como de la sociedad civil global (Bosniak, 2006; Delanty, 2000; Dahl, 2012; Delgado, 2012; Held, 1995; Miller, 2000; Mouffe, 
1992; Rodríguez-Guerra, 2013; Scholte, 2002). Si bien, Arendt, advierte los problemas para el ejercicio de la ciudadanía en el marco del Estado-nación, no elabora un análisis sobre las consecuencias reales que pueden tener las desigualdades sociales sobre las prácticas de las obligaciones cívicas. Tampoco la pensadora alemana estudia los problemas mundiales o globales que emanan de las relaciones de dominación entre los Estados para que la ciudadanía pueda desarrollarse con arreglo a sus ideales. Así, aunque en el pensamiento arendtiano se evidencia un claro esfuerzo por construir una propuesta de ciudadanía apropiada al contexto de las democracias contemporáneas, se hace necesaria, a partir de dicho pensamiento, una reflexión sobre las nuevas injusticias que aparecen en la sociedad global y que impiden que muchas de las personas que se mueven de un país a otro, en busca de una vida decente, posean los derechos humanos fundamentales cuando pasan a vivir en un país supuestamente democrático. Reflexión que ya inició Arendt al exponer lo siguiente: "El peligro estriba en que una civilización global e interrelacionada universalmente pueda producir bárbaros en su propio medio, obligando a millones de personas a llegar a condiciones que, a pesar de todas las apariencias, son las condiciones de los salvajes” (Arendt, 2001: 382).

Por tanto, la ciudadanía no ha de resignarse a asumir su simple papel de espectadora-gobernada en un escenario de grandes incertidumbres, profundas mudanzas y rupturas, como las que se derivan de las presentes sociedades crecientemente globalizadas en las cuales se empiezan a politizar muchos asuntos que hace poco permanecían incuestionados (Campillo, 2008; Delgado, 2012; Entrena, 2009; Scholte, 2002). Sin duda, tales incertidumbres, mudanzas y rupturas afectan a diversos ámbitos de la ciudadanía y a la misma calidad democrática. Si realmente tanto está en juego para el conjunto de la sociedad civil global, sería muy conveniente que la ciudadanía empezara a recuperar las riendas del espacio público para refundarlo con mimbres suficientemente consistentes y poder establecer acuerdos comunes.

En este sentido, es acertada la redefinición de la política que elabora Hannah, pues posibilita una propuesta de ciudadanía más en consonancia con las condiciones socio-políticas de las sociedades multiculturales del presente. En efecto, entender la política como esfera pública que emana de "las acciones libres y deliberadas" de la ciudadanía con capacidad de construir acciones y discursos, lleva a Arendt a liberar la política del monopolio del Estado, así como a emancipar a la ciudadanía de la mera administración de éste. Estas ideas contribuyen a replantear si el Estado y sus fronteras deben ser las únicas fuentes de ciudadanía (Bosniak, 2006: 25). En efecto, si la política deja de ser concebida como una tarea exclusiva de las instituciones del Estado, para transformarse en el espacio de interacción entre los seres humanos, la ciudadanía no sólo es un derecho otorgado al ser humano por el Estado en función de su pertenencia a él, sino que se transforma en un proceso construido consciente y responsablemente mediante la acción política en una comunidad humana plural. Así concebida, la propuesta de ciudadanía arendtiana se puede caracterizar como más inclusiva puesto que es independiente de la existencia del Estado. La ciudadanía es algo que el ser humano se brinda a sí mismo mediante su compromiso a largo plazo 
con la politeya, siendo ello una forma de enlazar la condición ciudadana con la dignidad humana.

\section{Bibliografía}

Alonso, V. (2012): "Lo que Hannah Arendt llamaba democracia", en Antonio Robles-Egea y Ramón Vargas-Machuca, Eds., La buena democracia. Claves de su calidad, Granada, Editorial Universidad de Granada.

Alonso, V. (2010): Retórica, democracia y crisis. Un estudio de teoría política, Madrid, Centro de Estudios Políticos y Constitucionales.

Amiel, A. (2001): La non-philosophie de Hannah Arendt. Révolution et jugement, París, Presses Universitaires de France (PUF).

Arendt, H. (2008): La promesa de la política, Barcelona, Paidós.

Arendt, H. (2007): Responsabilidad y juicio, Barcelona, Paidós.

Arendt, H. (2006a): Sobre la revolución, Madrid, Alianza.

Arendt, H. (2006b): Diario filosófico 1950-1973, Barcelona, Herder.

Arendt, H. (2005): La condición humana, Barcelona, Paidós.

Arendt, H. (2002): La vida del espíritu, Barcelona, Paidós.

Arendt, H. (2001): Los orígenes del totalitarismo, Madrid, Taurus (3a Edición).

Aristóteles (2007): Política, Madrid, Alianza.

Baños, J. (2008): El republicanismo cívico de Hannah Arendt: la relevancia de su pensamiento para las democracias contemporáneas, Madrid, Universidad Autónoma de Madrid. Tesis Doctoral.

Birulés, F. (2007): Una herencia sin testamento: Hannah Arendt, Barcelona, Herder. Bokiniec, M. (2009): "Is polis the answer? Hannah Arendt on democracy" Santalka Filosofija 17 (1): 76-82. http://www.thefreelibrary.com/Is polis the answer? Hannah Arendt on democracy/Ar polis yra atsakas?...-a0227281862

Bosniak, L. (2006): The Citizen and the Alien. Dilemmas of Contemporary Membership, Princeton, Princeton University Press.

Caloz-Tschopp, M.C. (2008): Résister en politique, résister en philosophie. Avec Arendt, Castoriadis et Ivekovic, París, La Dispute.

Campillo, A. (2008): El concepto de lo político en la sociedad global, Barcelona, Herder.

Camps, V. (2010): “El ejercicio cívico de la libertad de expresión”, en Victoria Camps, Ed., Democracia sin ciudadanos, Madrid, Trotta. 
Cano, S. (2004): Hannah Arendt: condiciones de posibilidad de la participación pública, Madrid, Universidad Complutense de Madrid. Tesis Doctoral.

Canovan, M. (1992): Hannah Arendt: A Reinterpretation of her Political Thought, Cambridge, Cambridge University Press.

Castells, M. (2009): Communication Power, Oxford, Oxford University Press.

Clarke, P.B. (2010): Ser ciudadano. Conciencia y praxis, Madrid, Sequitur.

Cruz, M. (2006): El siglo de Hannah Arendt, Barcelona, Paidós.

Crick, B. (2000): In Defence of Politics, Londres, Continuum The Tower Building. (Ed. Original: 1962).

Dahl, R.A. (2012): La democracia, Barcelona, Ariel.

Del Águila, R. (2009): "La inclasificable teoría política de Hannah Arendt”, en Ramón Máiz, comp., Teorías políticas contemporáneas, Valencia, Tirant lo Blanch.

Delanty, G. (2000): Citizenship in a global age: Society, Culture, Politics, Buckingham, Open University Press.

Delgado, S. (2012): "Ladrándole a la luna. Validez del proyecto cosmopolita a la luz de la calidad democrática”, en Antonio Robles-Egea y Ramón VargasMachuca, Eds., La buena democracia. Claves de su calidad, Granada, Editorial Universidad de Granada.

Entrena, F. (2009): "Understanding Social Structure in the Context of Global Uncertainties” Critical Sociology 35 (4): 521-540. doi: 10.1177/0896920509103982

Eslin, J.C. (1996): Hannah Arendt. L' obligée du monde, París, Éditions Michalon.

Flores D’Arcais, P. (2006): “Once tesis sobre Hannah Arendt” Claves de razón práctica 168:

http://dialnet.unirioja.es/servlet/articulo?codigo=2165232

Forti, S. (2006): Hannah Arendt tra filosofía e política, Milán, Bruno Mondadori.

Giner, S. (2006): "Hannah Arendt. La primacía moral de la política" Claves de razón práctica

168:

14-20.

http://dialnet.unirioja.es/servlet/articulo?codigo=2165233

Habermas, J. (1992): "Citizenship and National Identity. Some Reflections on the Future of Europe” Praxis International 12: 1-19.

http://getcited.com/cits/PP/1/PUB/103388659

Held, D. (1995): Democracy and the Global Order: from the modern state to cosmopolitan governance, Cambridge, Polity.

Kant, I. (2007): Crítica del Juicio, Madrid, Tecnos.

Kymlicka, W. y Norman, W. (1994): "Return of the Citizen: A Survey of Recent Work on Citizenship Theory" Ethics 104: 257-289. http://www.jstor.org/stable/2381582

Maravall, J. M. (2013): Las promesas políticas, Barcelona, Galaxia Gutenberg.

Marshall, D.L. (2010): “The Origin and Character of Hannah Arendt's Theory of Judgment” Political Theory 38 (3): 367-393. doi:10.1177/0090591709359595.

Mattucci, N. (2012): La politica esemplare. Sul pensiero di Hannah Arendt, Milán, FrancoAngeli. 
Miller, D. (2000): Citizenship and National Identity, Cambridge, Polity Press.

Montesquieu, C.S. (1987): Del espíritu de las leyes, Madrid, Tecnos.

Mouffe, CH. -Ed.- (1992): Dimensions of Radical Democracy: Pluralism, Citizenship, Community, Londres, Verso.

Pitkin, H. (1981): "Justice: On Relating Private and Public" Political Theory 9(3): 327-352. http://www.jstor.org/stable/191093

Ramírez, J.L. (2008): “La Retórica, fundamento de la ciudadanía y de la formación escolar en la sociedad moderna” Foro Interno 8: 11-38.

http://revistas.ucm.es/index.php/FOIN/article/view/FOIN0808110011A/784 0

Reyes-Mate, M. (2010): "Hannah Arendt y los derechos humanos” Revista Arbor: Ciencia, Pensamiento y Cultura 742: 241-243. doi: 10.3989/arbor.2010.742n1104

Rodríguez-Guerra, R. (2013): "El triunfo y las crisis de la democracia liberal" $\begin{array}{lllll}\text { Política } & y & \text { Sociedad, 60(2): }\end{array}$ http://dx.doi.org/10.5209/rev_POSO.2013.v50.n2.38989

Roiz, J. (2003): La recuperación del buen juicio. Teoría política en el siglo veinte, Madrid, Foro Interno.

Sahuí, A. (2002): "Hannah Arendt: espacio público y juicio reflexivo" Signos Filosóficos 8: 241-263. http://www.redalyc.org/articulo.oa?id=34300814

Sánchez, C. (2003): Hannah Arendt. El espacio público, Madrid, Centro de Estudios Políticos y Constitucionales.

Sánchez-Capdequí, C. (2012): “Movilidad, aceleración y banalidad del mal” Políti$\begin{array}{cccc}\text { ca } y & \text { Sociedad 49(3): }\end{array}$ http://dx.doi.org/10.5209/rev_POSO.2012.v49.n3.38543

Scholte, J.A. (2002): "Civil society and democracy in global governance" Global Governance 8(3): 281-304. http://www.jstor.org/stable/27800346

Tassin, É. (1998): Le trésor perdu. Hannah Arendt, l'intelligence de l'action politique, París, Éditions Payot.

Thaa, W. (2008): "Democracia y crítica de la civilización en Max Weber y Hannah Arendt” Revista Española de Ciencia Política 19: 9-40.

http://recp.es/index.php/recp/article/view/169/113

Tocqueville, A. de. (2006): La Democracia en América, Madrid, Alianza, Vol. II.

Torreblanca, J.I. (2011): “La democracia puesta a prueba” El País, 12 de noviembre. http://internacional.elpais.com/internacional/2011/11/12/actualidad/1321119086 848312.html

Vallespín, F. (2012): La mentira os hará libres. Realidad y ficción en la democracia, Barcelona, Galaxia Gutenberg.

Villa, D.R. (1998): “Presentación”, en Fina Birulés (ed.): Hannah Arendt: el legado de una mirada, Madrid, Sequitur, pp. 11-17.

Villa, D.R. (2002): The Cambridge Companion to Hannah Arendt, Cambridge, Cambridge University Press.

Walzer, M. (2004): Razón, pasión y política. 3 defectos del liberalismo, Madrid, Antonio Machado Libros. 
Wolin, S.S. (1983): "Hannah Arendt: Democracy and the Political” Salmagundi 60: 3-19. http://www.jstor.org/stable/40547750

Wolin, S.S. (2008): Democracia S.A. La democracia dirigida y el fantasma del totalitarismo invertido, Madrid, Katz Editores.

Young-Bruehl, E. (2006): Hannah Arendt. Una biografía, Barcelona, Paidós. 